\title{
BMJ Open Efficacy of a computer-tailored web- based physical activity intervention using Fitbits for older adults: a randomised controlled trial protocol
}

\author{
Stephanie Alley (D) , ${ }^{1}$ Jannique GZ van Uffelen, ${ }^{2}$ Stephanie Schoeppe, ${ }^{1}$ \\ Lynne Parkinson, ${ }^{3}$ Susan Hunt, ${ }^{4}$ Deborah Power, ${ }^{1}$ Mitch J Duncan (D) , ${ }^{5}$ \\ AG Schneiders, ${ }^{6}$ Corneel Vandelanotte ${ }^{1}$
}

To cite: Alley S, van Uffelen JGZ, Schoeppe $\mathrm{S}$, et al. Efficacy of a computer-tailored web-based physical activity intervention using Fitbits for older adults: a randomised controlled trial protocol. BMJ Open 2019;9:e033305. doi:10.1136/ bmjopen-2019-033305

- Prepublication history and additional material for this paper are available online. To view these files, please visit the journal online (http://dx.doi. org/10.1136/bmjopen-2019033305).

Received 30 July 2019

Revised 21 October 2019

Accepted 18 November 2019

Check for updates

(C) Author(s) (or their employer(s)) 2019. Re-use permitted under CC BY-NC. No commercial re-use. See rights and permissions. Published by BMJ.

For numbered affiliations see end of article.

Correspondence to Dr Stephanie Alley; s.alley@cqu.edu.au

\section{ABSTRACT}

Introduction Physical activity is an integral part of healthy ageing, yet the majority of older adults 65+ years are not sufficiently active. Web-based physical activity interventions hold much promise to reach older adults. Preliminary evidence suggests that web-based interventions with tailored advice and Fitbits may be well suited for older adults.

Methods and analysis This study aims to test the effectiveness of 'Active for Life', a 12-week computertailored web-based physical activity intervention using Fitbits for older adults. We will recruit 300 participants who will be randomly assigned to one of three trial arms: (1) web-based physical activity intervention with tailored advice only, (2) web-based physical activity intervention with tailored advice and Fitbit or (3) a wait-list control. The primary outcome, objective moderate to vigorous physical activity (MVPA) and secondary outcomes of objective sedentary behaviour, objective sleep, quality of life, social support, physical function and satisfaction with life will be assessed at baseline and week 12. The secondary outcomes of self-reported physical activity, sitting time and sleep will be assessed at baseline, week 6, 12 and 24. Website usability and participant satisfaction will be assessed at week 12 and website usage and intervention fidelity will be assessed from week 1 to 24 . Intention-totreat linear mixed model analyses will be used to test for group (tailoring only, tailoring +Fitbit, control) differences on changes in the main outcome, MVPA and secondary outcomes. Generalised linear models will be used to compare intervention groups (tailoring only, tailoring +Fitbit) on website usability, participant satisfaction, website usage and intervention fidelity.

Ethics and dissemination The study has received ethics approval from the Central Queensland University Human Research Ethics Committee (H16/12-321). Study outcomes will be disseminated through peer-reviewed publications and academic conferences and used to inform improvements and dissemination of a tailored, web-based physical activity intervention for adults $65+$ years.

Trial registration number Australian and New Zealand Clinical Trials Registry Number: ACTRN12618000646246
Strengths and limitations of this study

- This study addresses a need for affordable physical activity interventions targeting large numbers of older adults.

- This will be the first study to evaluate a web-based physical activity intervention with tailored advice and Fitbit integration developed for adults $65+$ years.

- Objective behavioural outcomes will be used to evaluate intervention effectiveness.

- Frequent contact with researchers may limit generalisability of findings to dissemination of the intervention in the 'real world'.

\section{INTRODUCTION}

Physical activity improves physical and mental health and reduces the risk of cardiovascular and other chronic diseases including diabetes and cancer. ${ }^{12}$ Physical activity also has specific benefits for older adults including improved mobility and function and a reduced risk of cognitive decline and falls. ${ }^{2}$ Active older adults 65 years and over are estimated to have a $22 \%$ lower risk of mortality than inactive older adults. ${ }^{1}$ Over $70 \%$ of older Australians do not meet the physical activity recommendations. ${ }^{3}$ Inactivity is costing Australia $\$ 13.8$ billion per year and the costs of inactivity increase with age. ${ }^{4}$ Australia has an ageing population and the number of adults $65+$ years is expected to rise from 3.8 million to 8.8 million by $2057,{ }^{5}$ leading to a rise in healthcare costs from $4.9 \%$ to $9.6 \%$ GDP. $^{6}$

Web-based physical activity interventions are effective at changing behaviour in middleaged adults, and they have the potential to reach large numbers of participants at low cost. ${ }^{78}$ Older adults $65+$ years are the fastest growing age group of internet users, with $79 \%$ of them already connected, ${ }^{9}$ and $85 \%$ of older internet users going online at least 
once a day. ${ }^{9}$ A number of studies have found web-based physical activity interventions to be effective in older adults. ${ }^{10}$ This includes a web-based intervention with self-monitoring and personal e-coaching in adults 60-70 years ${ }^{11}$ and a web-based intervention with physical activity education for workers over $50 .{ }^{12}$ However, most of these studies used existing interventions which were not specifically targeted to older adults and include adults younger than 65 years. ${ }^{10}$

Providing personally relevant physical activity advice is important for older adults due to wide differences in health and physical activity. ${ }^{3}$ Web-based personallytailored interventions deliver highly individualised advice by using an expert system (using IF-THEN algorithms; eg, IF not active, THEN provide feedback to increase activity levels) that automatically selects relevant feedback messages from a large database in response to participants' answers to brief online questionnaires. ${ }^{8}$ Advice can be tailored to participants' demographics, health status, activity levels and other factors. A study conducted by Ammann et $a l^{13}$ found that a web-based physical activity programme with tailored advice was more effective at increasing physical activity in adults over 60 years compared with adults under 60 years. This demonstrates the suitability of tailored physical activity advice for older adults, however, despite tailored advice being consistently shown to be effective, ${ }^{7}$ intervention effects are relatively small. ${ }^{14}$

Activity trackers (eg, Fitbit) which objectively measure physical activity have become popular for personal use and can improve the accuracy and credibility of tailored advice. ${ }^{15}$ Vandelanotte et $a l^{15}$ demonstrated improved effectiveness of a web-based tailored intervention in middle-aged adults when the personal advice was based on Fitbit activity tracker data compared with traditional self-reported physical activity. Older adults are less likely to have used an activity tracker compared with younger adults ${ }^{16}$; however, rates of activity tracker use are increasing in older adults and older adults use them for longer than their younger counterparts. ${ }^{17}$ It is currently unknown whether tailored advice based on integrated activity tracker data would improve the credibility and effectiveness of tailored advice as compared with advice based on self-reported physical activity in older adults.

Therefore, the first objective of this 3-group randomised trial is to determine the changes in objectively measured moderate to vigorous physical activity (MVPA) of participants assigned to a web-based computer-tailored physical activity programme for older adults (with and without activity tracker integration) compared with a control group. The second objective is to determine changes in objectively measured MVPA of participants assigned to a web-based computer-tailored physical activity programme for older adults with Fitbit integration compared with participants assigned to a web-based computer-tailored physical activity programme without Fitbit integration.

\section{METHODS}

\section{Procedures and participants}

\section{Recruitment}

Participants will be recruited in Rockhampton (Regional Queensland, Australia), Bundaberg (Regional Queensland Australia) and Adelaide (Metropolitan South Australia, Australia), through flyers, posters, notices in newsletters, word of mouth, Facebook posts, Facebook advertisements (figure 1) and email lists (eg, CQUniversity staff, CQUniversity alumni, former 10000 Steps members). Prospective participants will be directed to a website (figure 2) with a summary of the study and a detailed participant information form. A 'sign up' button will take prospective participants to an online screening questionnaire.

\section{Eligibility criteria}

Eligible participants will be over 65 years of age, not meeting the physical activity recommendations of $30 \mathrm{~min}$ of physical activity on 5 days a week, be able to attend a baseline and follow-up session at one of the project offices, have easy access to a computer, tablet or smartphone with internet connection and feel confident using the internet to do basic tasks. Prospective participants will be deemed ineligible if they are currently participating in a physical activity programme or have used an activity tracker (eg, Fitbit, Garmin, pedometer) in the last 12 months. These criteria will each be assessed via a single question with yes or no response options. Participants will also be asked to complete the Physical Activity Readiness Questionnaire (PARQ) ${ }^{18}$ as part of the screening questionnaire to ensure they do not have any conditions preventing them from safely increasing their physical activity. Those who do not pass the PARQ will be asked to confirm via a single question that they have obtained medical clearance from their general practitioner (GP) to increase their physical activity before participating. Eligible participants will receive an automatic message at the end of the screening questionnaire that they will be contacted by a researcher to sign them up to the project and ineligible participants will receive an automatic message explaining why they are not eligible.

\section{Data collection}

Eligible participants will be asked to complete an online consent form and four research questionnaires at baseline, week 6,12 and 24. All participants will be posted a GT9X wrist-worn accelerometer to wear for seven consecutive days including when sleeping and showering (but not swimming) at baseline and week 12. The accelerometer will collect data on the primary outcome measure, objective physical activity behaviour as well as objective sedentary behaviour and sleep. A log sheet will also be posted to participants for them to record accelerometer wear time and sleep and wake times. Participants will be required to attend a face-to-face appointment with a research officer at baseline and week 12 where they will return their accelerometer and log sheet. Participants 


\section{- Active For Life CQUni Sponsored 6}

\section{Active For Life is a free online physical activity program for adults $65+$ years. Take the first step to improving your health and sign up today!}

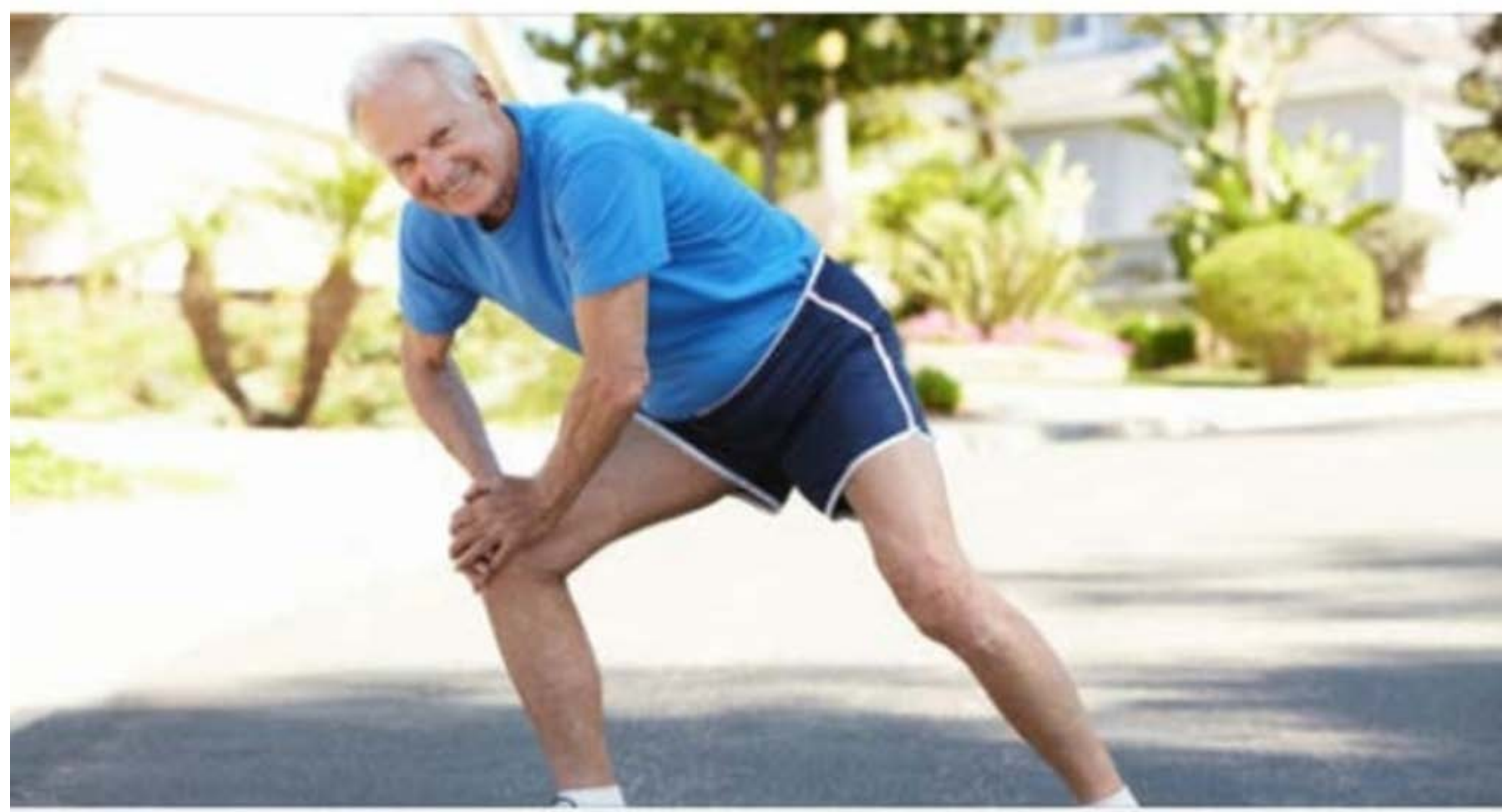

\section{ACTIVEFORLIFE.NET.AU}

\section{Active For Life: Join}

\section{Learn More}

\section{Register now for this FREE web-based exercise program...}

Figure 1 Example of Facebook advertisement. Source: Facebook ads manager (facebook.com/adsmanager).

who have not finished the baseline questionnaire will be asked to complete it during the baseline appointment.

\section{Randomisation}

After completing all baseline assessments, participants will be randomly assigned by a research officer to one of the intervention groups (Tailoring-only, Tailoring +Fitbit, Wait-list Control) using computer automated block randomisation (block size $=15$ ) with a 1:1:1 ratio. Participant randomisation will be stratified by age (under 75 , over 75 ) and gender (male, female) to ensure equal distribution of age and gender across groups. All research officers will randomise participants and guide them through the intervention they are allocated to during the baseline appointment. Therefore, neither participants or research officers will be blinded to group allocation. Participants from both intervention groups will be given access and log-in details to the intervention, 'Active for Life' and shown through the website. The tailoring +Fitbit participants will also be given a Fitbit, shown how to sync it to the website and asked to wear it to track their activity during the entire 12 week intervention. The first intervention module will be available to Tailoring-only participants immediately after the baseline appointment as they can self-report their activity from the prior week. However, the tailoring + Fitbit participants will receive access to the first module a week after the baseline appointment so that their Fitbit can collect a week of physical activity data prior to the accessing and completing the first intervention module. Wait-list control participants will be given access to the intervention after all outcome measures are collected (week 24).

Ethical considerations

Participants will receive up to three reminder emails if they do not complete the research questionnaires within the allocated time frame. If the questionnaires are still not 


\title{
Welcome to Active For Life
}

\author{
Do you want to be more active and improve your health? You have \\ come to the right place! \\ This personally tailored website will help you to become more active in a fun and educational \\ way! Start feeling healthy again. Best of all: it's FREE!
}

Already registered? Login now

To see what's involved, please read the details about the Active for Life Project here:

\begin{abstract}
Participant Information Sheet
The effectiveness of an internet-based physical activity intervention with tailored advice targeting adults $65+$ years.

Thank you for your interest in participating in this research. This research is being conducted through the Physical Activity Research Group based at CQUniversity.

Physical activity reduces risk of disease and leads to improved physical and mental health. Access to the internet
\end{abstract}

Figure 2 Active for life landing page. Source: active for life intervention website (www.activeforlife.net.au).

completed participants will be offered $\$$ A20 to complete it. Participants who comply with all study procedures will receive \$A50. Participants can remain in the trial if they missed an outcome measure or have not completed intervention modules. If participants choose to withdraw from the trial their previously collected data will remain in the trial data set unless they request to have it removed. Recruitment and data collection will be managed by five research officers. Annual ethics reports will be submitted to the committee and participants will be given details of the ethics committee to report any adverse outcomes. Modifications to trial protocols will be reported to the ethics committee and trial registry. Individually identifiable data will be stored on password-protected computers accessible by study authors. The data will be saved in non-identifiable format for use of other investigators and storage post study completion. See figure 3 for a flow chart of the study design.

\section{Patient and public involvement}

We did not involve patients or public in the design, conduct or reporting of the research. However, six focus groups were conducted with a total of 46 adults 65+ years to inform the development of the Active for Life intervention.

\section{Intervention}

Participants in both intervention groups will receive access to a 12-week web-based computer-tailored physical activity intervention, Active for Life (see figure 4). Active for Life was based on the 'My Activity Coach' intervention which is effective in inactive middle-aged adults. ${ }^{8}$ The intervention was updated based on findings from focus groups investigating the perceptions and preferences of web-based physical activity interventions in adults $65+$ years. This included adding sections on the physical activity guidelines for older adults, strength and balance exercises and exercising with illnesses and injury. ${ }^{19}$ Existing sections including benefits, barriers, self-efficacy, active lifestyles and action planning were modified to be relevant and engaging to adults $65+$ years. Active for Life includes six modules released bi-weekly pending prior module completion. The modules provide participants with personalised physical activity advice based on their responses to a brief survey on their personal characteristics (eg, health status, body mass index) and psychosocial correlates of physical activity (eg, self-efficacy, social support) at the start of each module. The advice is automatically selected from a database using IF-THEN algorithms (eg, IF inactive THEN provide advice to increase physical activity). Figure 5 and online supplementary File 1 show the format of the advice and advice content 


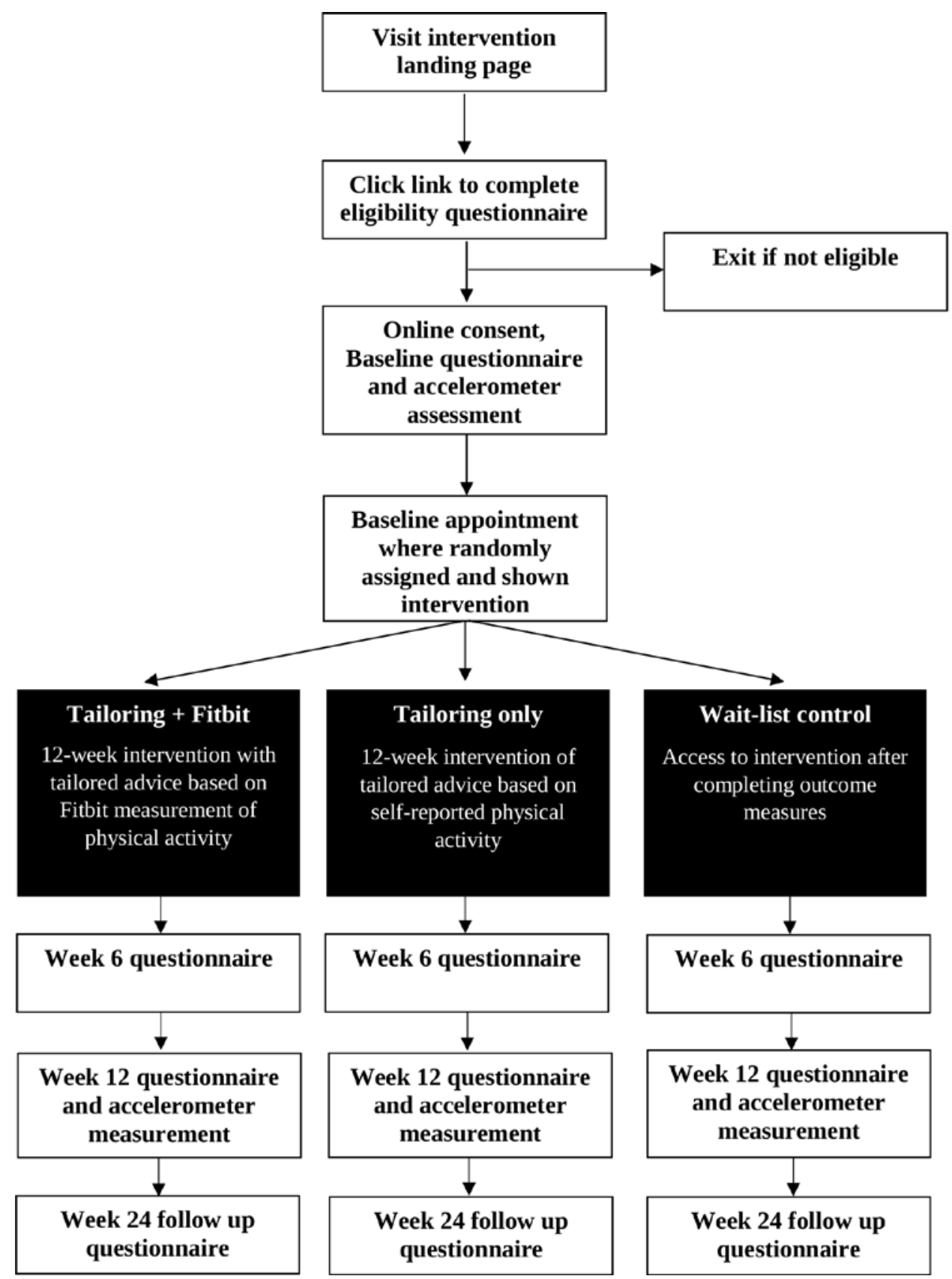

Figure 3 Flow chart of study design.

that a participant may receive. Participants will be sent up to three reminder emails at 2-day intervals when each module becomes available. Participants who miss or complete a module late can catch up and still complete the intervention in 12 weeks.

The tailored modules are based on the theory of planned behaviour $^{20}$ and social cognitive theory ${ }^{21}$ and as such target participants' attitudes (eg, benefits and barriers), outcome expectancy, self-efficacy, social support and subjective norms (eg, activity levels of friends) for physical activity. The use of evidence-based behaviour change techniques (ie, goal setting, self-monitoring, action planning, prompts and cues, rewards and relapse prevention) is also integrated into the intervention. ${ }^{22}$ Furthermore, instruction on physical activity recommendations, safety when exercising, sedentary behaviour and incidental activity are covered (see table 1 ).

The only difference between intervention groups is that the Tailoring-only participants will self-report their physical activity as part of each modules' survey and the Tailoring +Fitbit participants' physical activity data will be recorded via their Fitbit device and synced with the website through a single button to automatically prefill the physical activity survey questions. As such, the number of minutes of light, moderate and vigorous physical activity the participant completed in the previous week will be collected from the Fitbit. The Fitbit Flex will be provided to the Tailoring +Fitbit participants. The Flex model does not have a display except for five LED lights which individually light up for every 2000 steps taken in a day. 


\section{Actı\% \\ FOR LIFE}

\section{Hi Anne, let's get started!}

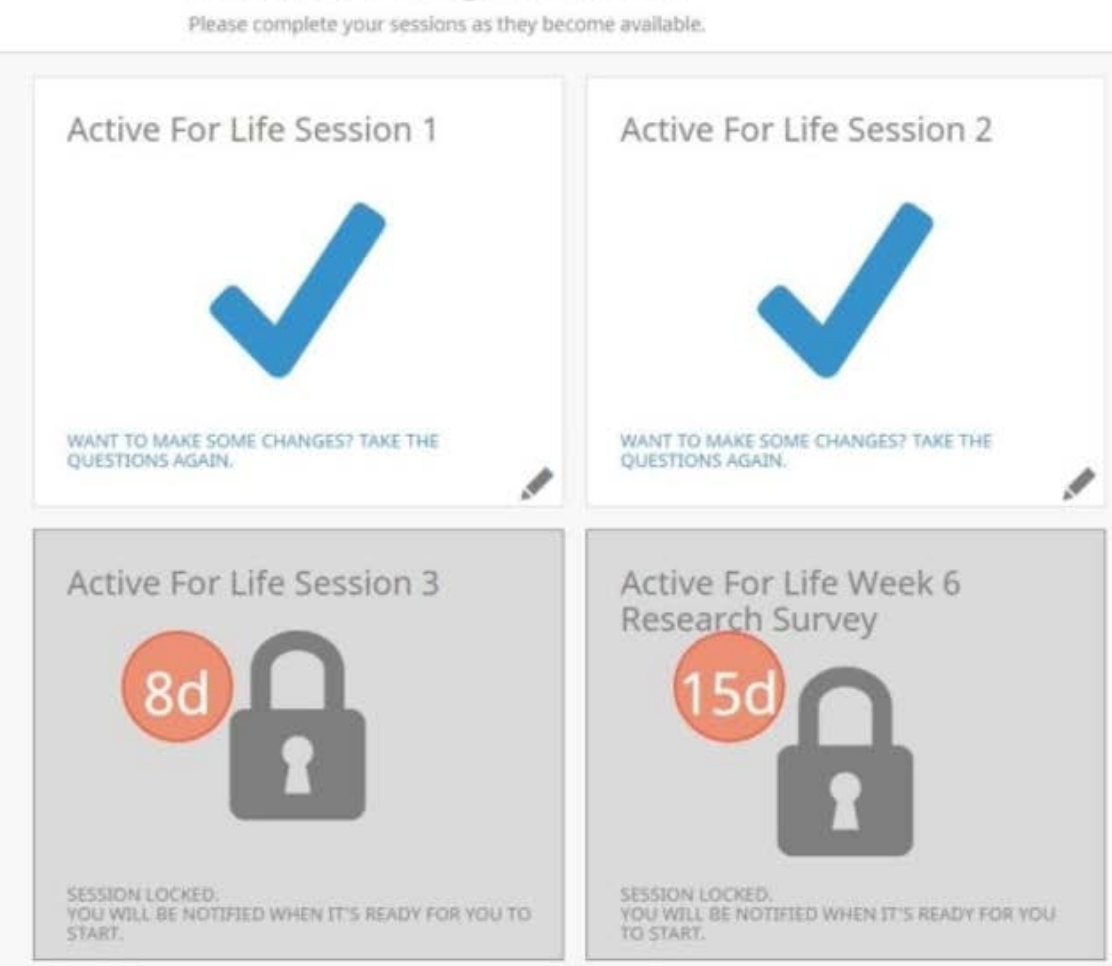

My Action Plan 1 Action planning and Goal setting tool

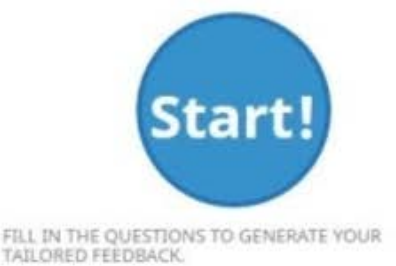

Figure 4 Active for life dashboard. Source: active for life intervention website (www.activeforlife.net.au).

The Active for Life intervention includes an action planning tool where participants are guided in completing two action plans (weeks 2 and 4 ) of their physical activity for the following fortnight. This includes the what, where, when, duration and companions for the planned physical activity. An exercise library is also provided for participants who want to follow a programme of strength, flexibility and balance training exercises. A 4-week beginners programme and a 4-week intermediate programme are available. Participants can view and/or print a description, frequency and duration of the exercises and if interested can follow a link to an external website (www. physiapp.com) to view videos illustrating the exercises.

\section{Measures}

Wrist-worn ActiGraph GT9X Accelerometers will be used to objectively track physical activity, sedentary behaviour and sleep. At baseline and week 12, participants will be asked to wear the accelerometer on their non-dominant wrist for seven consecutive 24-hour days including when sleeping and showering. Participants will be asked to $\log$ their accelerometer wear time and sleep and wake times on a $\log$ sheet. Participants will be asked to take off the device for swimming and to record the activity in their $\log$ book. Acceleration will be recorded at $30 \mathrm{~Hz}$. When calculating the physical activity data, valid wear time will be defined as at least 16 hours each day on a minimum of 5 days. Non-wear time will be calculated using a previously reported algorithm. ${ }^{23}$ Euclidean norm minus One values expressed as milligravity $(\mathrm{mg})$ and averaged over $5 \mathrm{~s}$ epochs will be used to record acceleration. Light, moderate and vigorous physical activity will be classified as $\geq 30, \geq 100$ and $\geq 400 \mathrm{mg}$, respectively. ${ }^{24}{ }^{25}$ Sedentary behaviour will be classified as $<30 \mathrm{mg}$. Sleep analysis will be guided by the sleep log. Accelerometer data will be processed using the GGIR package in R. ActiGraph monitors are valid compared with other activity monitors. ${ }^{26}$

Demographic factors will be collected via a questionnaire at baseline. These are gender, age, marital status (single, widowed, divorced, separated, married, de facto), English as main language (yes/no), education (none, preschool, primary school, secondary school, technical college, university), years of education, residential location (city, town, rural area), postcode, height, weight, work status (unemployed, retired, student, home duties, casual, part-time, full time), work type (white collar, blue collar, professional), pretax household income (none$5000+$ perweek) and current health diagnoses (eg, osteoporosis, diabetes).

Internet and technology use will be measured at baseline. Three items adapted from Blank and Groselj ${ }^{27}$ will 


\title{
Actro

\begin{abstract}
Are you meeting the guidelines?
Our calculations show that on average you're doing 180 minutes of moderate or vigorous physical activity per week. The graph below shows how active you are currently and whether you meet the Australian minimum and optimal physical activity guidelines. Well done, the graph shows that you are active enough to enjoy the health benefits! You are doing a fantastic job! There is however room for you to further increase your physical activity. You will receive additional health benefits if you can bring your activity levels up to the 'optimal' guideline of 300 minutes per week (ie. 60 minutes on 5 days of the week).
\end{abstract}

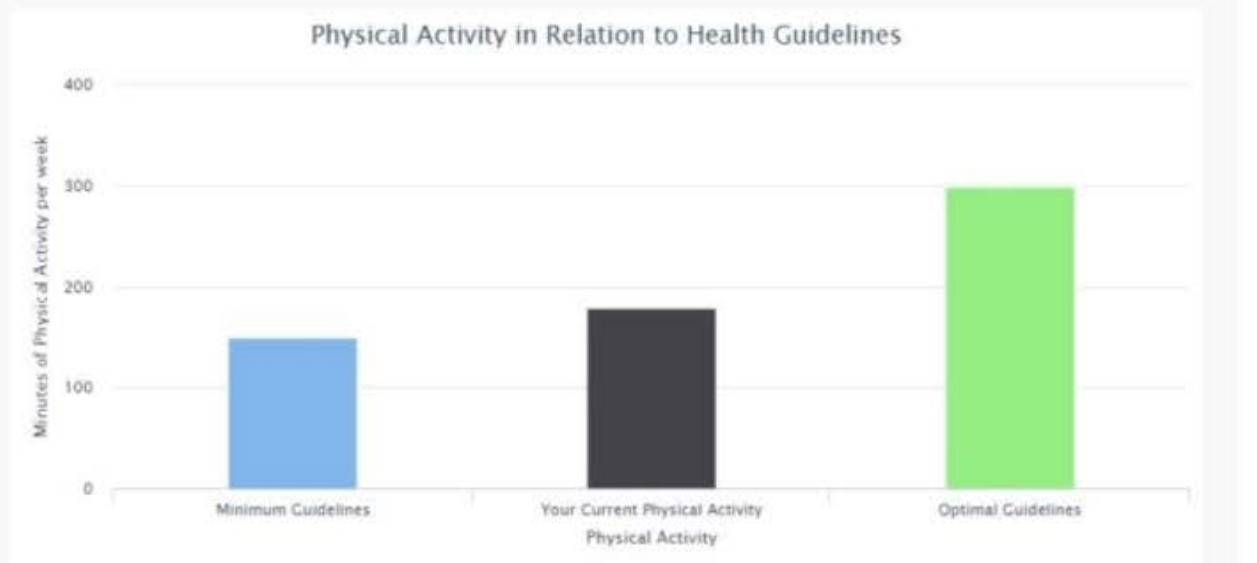

Figure 5 Active for life tailored advice. Source: active for life intervention website (www.activeforlife.net.au).

assess how frequently participants use the internet with seven response options from 'never' to 'most of the day', average length of each session of internet use and internet connection speed with five response options from 'very slow' to 'very fast'. Four items based on past research $^{28}$ will be used to assess how often participants use a computer, smart phone, tablet and/or social media with three response options from 'a few times a month' to 'a few times a day'.

Internet self-efficacy will be assessed using the Internet Self-Efficacy Scale. The scale includes nine items of tasks related to internet use (eg, using the internet to gather data) which participants are asked to rate on a 7-point Likert scale from 'strongly agree' (7) to 'strongly disagree' (1). Higher scores indicate higher internet self-efficacy. The scale is reliable and validated against internet use and experience. ${ }^{29}$

Interest in physical activity interventions will be assessed at baseline using four items based on past research. ${ }^{28}$ Participants will be asked if they are interested in using an activity monitor, how often they would like to use it and the type of monitor they would prefer to use (eg, advanced tracker or pedometer). Participants will also be asked to indicate using a check list if they would be interested in five physical activity intervention types including online, smart phone application, one-on-one programme, groupbased programme and/or paper-based programme.

Participants' total physical activity will be measured through the Active Australia Survey at baseline, week 6, 12 and 24. The 8-item survey assesses participants' time spent in walking, moderate intensity activity and vigorous intensity activity over the past week. Total physical activity will be calculated by summing the time spent walking, time spent in moderate intensity activities and the time spent in vigorous activities weighted by two according to manual instructions. ${ }^{30}$ The survey has a good test-retest reliability (intraclass coefficient $=0.64)^{31}$ and is validated against pedometer step counts in older adults $(r=0.42) .^{32}$

Participation in strength, balance and flexibility activities will be recorded at baseline, week 6, 12 and 24. Participants will be asked to report the number of sessions, number of exercises and number of repetitions for strength activities in the last week. Participants will also be asked to report the number of sessions of balance and flexibility activities of at least $30 \mathrm{~min}$ duration in the last week.

Sitting time will be measured through the Workplace Sitting Questionnaire at baseline, week 6, 12 and 24. The questionnaire measures minutes of sitting time per week during work, television viewing, computer-use outside 
Table 1 Content of the six sessions of 'Active for Life'

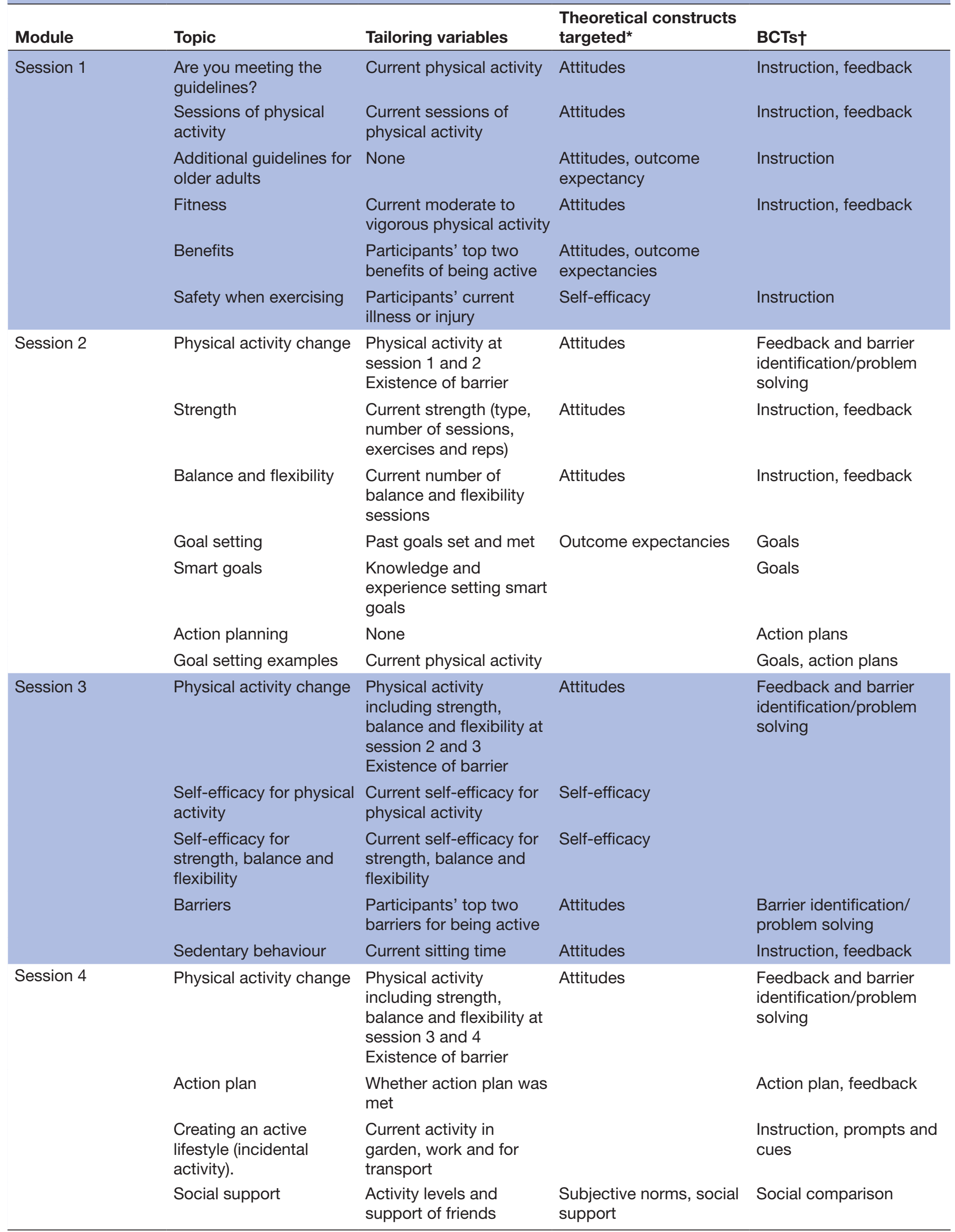


Table 1 Continued

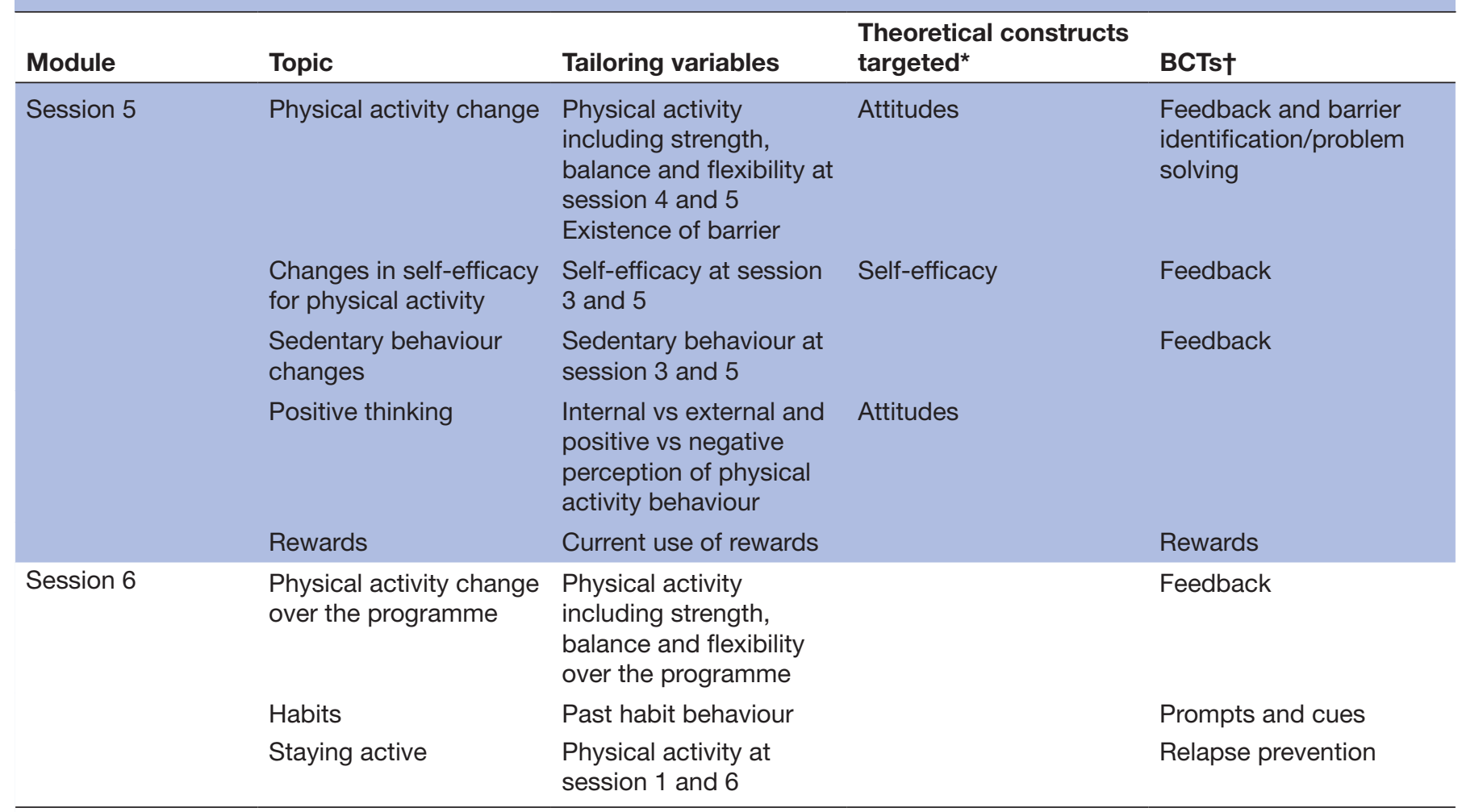

${ }^{*}$ Theoretical constructs of the Theory of Planned Behaviour and Social Cognitive theories. ${ }^{20} 21$ †BCTs of Michie et al..$^{22}$

BCT, Behaviour Change Techniques.

work, transport and other leisure-time activities on work and non-workdays. Average daily sitting in each domain and average total daily sitting will be calculated for work and non-work days. This will be multiplied by the number of work and non-work days respectively, divided by seven and converted to hours $(\mathrm{min} / 60)$ to produce average sitting in each domain (hours/day) and average total daily sitting (hours/day). Estimates of both workday and non-workday sitting has adequate test-retest reliability (ICC=0.46-0.90) and validity compared with accelerometry in women $(\mathrm{r}=0.22-0.46)$ and men $(\mathrm{r}=0.18-0.29){ }^{33}$

Sleep quality will be measured through five questions of the Behavioural Risk Factor Surveillance System survey $(\text { BRFSS })^{34}$ and one question of the reliable Pittsburgh Sleep Quality Index ${ }^{35}$ at baseline, week 6, week 12 and week 24. BRFSS is a population survey conducted in the U.S on more than 400000 participants annually. Four questions will be used to assess inadequate sleep and two questions will be used to assess perceived insufficient rest or sleep.

Social support will be measured through the 11-item Duke Social Support Index at baseline and week 12. The questionnaire asks participants how many people they depend on and the frequency of three types of social interactions (face-to-face, telephone, meetings). The sum of responses to these four questions makes a social interaction subscale where higher scores indicate more social interaction. Six questions assess how connected participants feel (eg, do you know what is going on with your family and friends) and a final question assesses how satisfied participants are with their relationships. The sum of responses to these seven questions make up a subjective support subscale where higher scores indicate more social support. The questionnaire is valid and reliable in older adults. ${ }^{36}$

Quality of life will be measured through the 12-item revised Short Form Health Survey (SF-12) at baseline and week 12. The SF-12 measures physical functioning, role participation with physical health problems, bodily pain, general health, vitality, social functioning, role participation with emotional health problems and mental health. A physical health component and mental health component score are calculated using norm based standardised scores. The SF-12 is widely used, reliable and valid in older adults. ${ }^{37}$

Satisfaction with Life will be measured using the Satisfaction with Life scale at baseline and week 12. The scale includes five statements about satisfaction with life (eg, In most ways my life is close to ideal) with responses on a 7-point Likert scale ranging from strongly agree (7) to strongly disagree (1). Items are summed with higher scores indicating higher satisfaction. The scale has shown good psychometric properties in older adult populations. ${ }^{38} 39$

Physical Function will be measured through the physical function sub-scale of the Functional Status Questionnaire at baseline and week 12. Nine items of everyday tasks are included for which participants are asked to select from 'usually did with no difficulty' (4), 'some difficulty' (3), 
'much difficulty' (2) or 'usually did not do because of health' (1). Responses are summed with higher scores representing higher functional status. The questionnaire is valid and reliable for older adults. ${ }^{40} 41$

Website usability will be assessed via the System Usability Scale at week 12. The scale includes 10 items about use of the website (eg, I thought the system was easy to use) with responses on a 5-point Likert scale ranging from 'strongly agree' (5) to 'strongly disagree' (1). Negative items are reverse scored, scores for each item added together and the total multiplied by 2.5 to make a scale between $0-100$. Scores above 68 represent good website usability. The questionnaire is valid and reliable. ${ }^{42}$

Intervention satisfaction will be recorded at week 12 . The questions are specifically developed for this study but based on past research. ${ }^{15}$ Nine items about the tailored advice will be presented (eg, the physical activity advice is credible) with responses options on a 5- point Likert scale ranging from 'strongly agree' to 'strongly disagree'. Participants will be asked if they used the action planning tool and library of exercises and if so to indicate how useful each feature was using a 5-point Likert scale ranging from 'not very useful' to 'very useful'. Participants will also be asked how useful they found the whole programme using a 5-point Likert scale ranging from 'not very useful' to 'very useful'. Lastly, 5 open ended questions will be used to give participants the opportunity to present any other feedback they have about the personalised advice, action planning tool, library of exercises and overall programme.

Intervention fidelity will be measured by completion of each of the six modules. This data will be recorded objectively through the intervention website database.

Website user statistics will be recorded through Google Analytics. These statistics include number of log-ins, pages visited and time spent on website for the entire duration of the intervention (12 weeks).

Fitbit satisfaction will be assessed through 10 questions at week 12. Questions are based on past research. ${ }^{15}$ Eight statements are used to assess satisfaction with the use of the Fitbit to inform the tailored advice (eg, to improve the credibility of the tailored advice) with response options on a 5-point Likert scale from strongly disagree to strongly agree. Two open ended questions are used to assess what participants liked and disliked about using the Fitbit in the study.

Fitbit use will be assessed via four questions at week 12 and 24. Questions based on past research ${ }^{15}$ will assess length and frequency of Fitbit use. See table 2 for an overview of study measures.

\section{Sample size}

To detect between group differences in objectively measured MVPA at 12 weeks, the required sample size is 100 participants per group. This is based on an effect size of 0.37 which is clinically and statistically significant ${ }^{7}$ (power $=0.80$; alpha $=0.05$ ). Therefore, 300 participants will be needed.

\section{Data analysis}

For the main outcome comparing groups (Tailoringonly, Tailoring +Fitbit, Control) on changes in physical activity, an intention-to-treat linear mixed model analysis using restricted maximum likelihood estimation will be conducted. For this analysis, a group (Tailoring +Fitbit, Tailoring-only, Control) by time (baseline, week 12) interaction on objectively measured physical activity will be tested.

Additional linear mixed model analyses will be conducted to compare groups on changes in secondary outcomes (sleep and sedentary behaviour, quality of life, social support, physical function status and satisfaction with life). For these analyses, a group (Tailoring +Fitbit, Tailoring-only, Control) by time (baseline, week 12) interaction on each secondary outcome will be tested. To compare groups on self-reported physical activity, sedentary behaviour and sleep changes from baseline to mid-intervention, post-intervention and follow-up, intention-to-treat linear mixed models using restricted maximum likelihood estimation will be conducted. For these analyses, a group (Tailoring +Fitbit, Tailoring-only, Control) by time (baseline, week 6, week 12, week 24) interaction on self-reported physical activity, sitting time and sleep quality will be tested.

Five generalised linear models will be used to compare intervention groups (Tailoring-only, Tailoring +Fitbit) on website usability, participant satisfaction, website usage (website visits and time on website) and intervention fidelity. The models and link functions will be selected after inspecting the distributions of each outcome variable. Sensitivity analyses will be conducted by adjusting all analyses for participant characteristics (including demographics, internet self-efficacy, internet and technology use) found to be associated with outcome variables. All analyses will be conducted using SPSS V.24 with an alpha of 05 .

\section{Ethics and dissemination}

Study outcomes will be disseminated through peerreviewed publications and academic conferences and used to inform improvements and dissemination of a tailored, web-based physical activity intervention for adults $65+$ years.

\section{DISCUSSION}

Due to the physical and mental health benefits of physical activity for healthy ageing ${ }^{12}$ and the low levels of physical activity in older adults, ${ }^{3}$ affordable physical activity interventions with the potential to reach large numbers of older adults are needed. Web-based physical activity programme have been found to be more effective in older compared with younger participants ${ }^{13}$ and therefore hold much promise for older adults. Despite this very few web-based physical activity interventions have been built specifically for adults $65+$ years. ${ }^{10}$ The lack of web-based physical activity interventions for older 
Table 2 Study outcomes and measures

\begin{tabular}{|c|c|c|c|c|}
\hline Outcome & Measure & Number of items & Time point & Groups \\
\hline Demographic factors & $\begin{array}{l}\text { Items commonly used in } \\
\text { previous research }\end{array}$ & 14 & Baseline & All \\
\hline $\begin{array}{l}\text { Internet and } \\
\text { technology use }\end{array}$ & $\begin{array}{l}\text { Items used in previous } \\
\text { research } 2728\end{array}$ & 7 & Baseline & All \\
\hline Internet self-efficacy & Internet self-efficacy scale ${ }^{29}$ & 9 & Baseline & All \\
\hline $\begin{array}{l}\text { Interest in physical } \\
\text { activity interventions }\end{array}$ & $\begin{array}{l}\text { Items used in previous } \\
\text { research }\end{array}$ & 4 & Baseline & All \\
\hline \multirow[t]{2}{*}{ Physical Activity } & GT9X Accelerometer ${ }^{26}$ & N/A & Baseline, Week 12 & All \\
\hline & Active Australia Survey ${ }^{30}$ & 8 & $\begin{array}{l}\text { Baseline, Week 6, } \\
\text { Week 12, Week } 24\end{array}$ & All \\
\hline $\begin{array}{l}\text { Strength, balance and } \\
\text { flexibility activities }\end{array}$ & $\begin{array}{l}\text { Items formulated for the current } \\
\text { study }\end{array}$ & 4 & $\begin{array}{l}\text { Baseline, Week } 6 \text {, } \\
\text { Week 12, Week } 24\end{array}$ & All \\
\hline \multirow[t]{2}{*}{ Sedentary behaviour } & GT9X Accelerometer $^{26}$ & N/A & Baseline, Week 12 & All \\
\hline & $\begin{array}{l}\text { Workforce sitting } \\
\text { questionnaire }^{33}\end{array}$ & 11 & $\begin{array}{l}\text { Baseline, Week } 6 \text {, } \\
\text { Week 12, Week } 24\end{array}$ & All \\
\hline Sleep behaviour & GT9X Accelerometer ${ }^{26}$ & $\mathrm{~N} / \mathrm{A}$ & Baseline, Week 12 & All \\
\hline Sleep quality & $\begin{array}{l}\text { Five questions of the } \\
\text { Behavioural Risk Factor } \\
\text { Surveillance System } \\
\text { Survey }{ }^{34} \text { and one question of } \\
\text { the Pittsburgh Sleep Quality } \\
\text { Index }{ }^{35}\end{array}$ & 6 & $\begin{array}{l}\text { Baseline, Week 6, } \\
\text { Week 12, Week } 24\end{array}$ & All \\
\hline Social Support & Duke Social Support Index ${ }^{36}$ & 11 & Baseline, Week 12 & All \\
\hline Quality of life & Short Form Health Survey ${ }^{37}$ & 12 & Baseline, Week 12 & All \\
\hline Satisfaction with Life & Satisfaction with Life scale ${ }^{38} 39$ & 5 & Baseline, Week 12 & All \\
\hline Physical Function & $\begin{array}{l}\text { Physical function sub-scale } \\
\text { of the Functional Status } \\
\text { Questionnaire }^{40}\end{array}$ & 9 & Baseline, Week 12 & All \\
\hline $\begin{array}{l}\text { Intervention } \\
\text { satisfaction }\end{array}$ & $\begin{array}{l}\text { Items used in previous } \\
\text { research }\end{array}$ & 26 & Week 12 & $\begin{array}{l}\text { Tailoring only and Tailoring } \\
\text { +Fitbit }\end{array}$ \\
\hline Fitbit satisfaction & $\begin{array}{l}\text { Items used in previous } \\
\text { research }\end{array}$ & 10 & Week 12 & Tailoring +Fitbit \\
\hline Fitbit use & $\begin{array}{l}\text { Items used in previous } \\
\text { research }{ }^{15}\end{array}$ & 4 & Weeks 12 and 24 & Tailoring +Fitbit \\
\hline Website usability & System Usability Scale ${ }^{42}$ & 10 & Week 12 & $\begin{array}{l}\text { Tailoring only and Tailoring } \\
+ \text { Fitbit }\end{array}$ \\
\hline Intervention fidelity & $\begin{array}{l}\text { Objective completion of the six } \\
\text { modules }\end{array}$ & $\mathrm{N} / \mathrm{A}$ & $\begin{array}{l}\text { Continuous from } \\
\text { Baseline to Week } 12\end{array}$ & $\begin{array}{l}\text { Tailoring only and Tailoring } \\
+ \text { Fitbit }\end{array}$ \\
\hline Website user statistics & Google Analytics & $\mathrm{N} / \mathrm{A}$ & $\begin{array}{l}\text { Continuous from } \\
\text { Baseline to Week } 12\end{array}$ & $\begin{array}{l}\text { Tailoring only and Tailoring } \\
+ \text { +Fitbit }\end{array}$ \\
\hline
\end{tabular}

adults may be due to the stereotype that older adults are low internet users and therefore do not engage in webbased health programme. This view is becoming quickly outdated as older adults are the fastest growing group of internet users. ${ }^{9}$ Preliminary evidence suggests that the use of tailored physical activity advice and a commercial activity tracker to inform the tailored advice is well suited to older adults. ${ }^{13} 17$ Therefore, this study will determine the effectiveness of a web-based physical activity intervention with tailored advice built specifically for adults 65+ years. The effectiveness of a popular commercial activity tracker (Fitbit) to track physical activity and inform the tailored physical activity advice in older adults will also be tested. Strengths of the study include the use of an intervention built specifically for older adults, the sample of adults being $65+$ years only and the use of objective physical activity and website usage assessments. A limitation of the study is the frequent contact with researchers which may impact participants' engagement with the intervention and their behavioural outcomes. Therefore, the findings may not be generalisable to dissemination of the intervention in the 'real world' where participants will 
not be contacted by researchers. Results from this study will inform future wide-reaching programme using new technology to promote physical activity in older adults.

\section{Author affiliations}

${ }^{1}$ School of Health, Medical and Applied Sciences, Appleton Institute, Physical Activity Research Group, CQUniversity, Rockhampton, Queensland, Australia

${ }^{2}$ Department of Kinesiology, KU Leuven, Leuven, Belgium

${ }^{3}$ School of Nursing, Midwifery and Social Sciences, Central Queensland University, Bundaburg, Queensland, Australia

${ }^{4}$ School of Nursing, Midwifery and Social Sciences, Central Queensland University, Melbourne, Victoria, Australia

${ }^{5}$ School of Medicine \& Public Health, Priority Research Centre for Physical Activity and Nutrition, Faculty of Health and Medicine, University of Newcastle, Callaghan, New South Wales, Australia

${ }^{6}$ School of Health, Medical and Applied Sciences, Central Queensland University, Bundaburg, Queensland, Australia

\section{Twitter Mitch J Duncan @mitchjduncan and Corneel Vandelanotte @corneelvdl}

Contributors SJA conceived the study, contributed to study design, created the intervention modules and wrote the manuscript, JGZvU contributed to study design and manuscript write up, LP contributed to the study design and manuscript write up, SS contributed to the study design and manuscript write up, SH contributed to the study design and manuscript write up, DP managed data collection and contributed to manuscript write up, MJD contributed to objective measurement protocols and manuscript write up, AS contributed to study design and manuscript write up and CV conceived the study, supervised the study and contributed to manuscript write up.

Funding The trial was funded by a grant from Central Queensland University ( research-grants@cqu.edu.au, RSH3796) and the National Heart Foundation (ID100427). MJD is supported by a Career Development Fellowship (GNT1141606) from the National Health and Medical Research Council and CV is supported by a Future Leader Fellowship from the National Heart Foundation (ID100427). SS is supported by an Early Career Fellowship from the National Health and Medical Research Council of Australia (GNT1125586) and a Postdoctoral Fellowship from the National Heart Foundation of Australia (ID101240).

Disclaimer Funding agencies will play no role in study design, data collection, analysis or in reporting outcomes.

Competing interests None declared.

Patient consent for publication Not required.

Ethics approval Ethics approval was received from the Central Queensland University Human Research Ethics Committee (H16/12-321) before data collection.

Provenance and peer review Not commissioned; externally peer reviewed.

Data availability statement There are no data in this work.

Open access This is an open access article distributed in accordance with the Creative Commons Attribution Non Commercial (CC BY-NC 4.0) license, which permits others to distribute, remix, adapt, build upon this work non-commercially, and license their derivative works on different terms, provided the original work is properly cited, appropriate credit is given, any changes made indicated, and the use is non-commercial. See: http://creativecommons.org/licenses/by-nc/4.0/.

\section{ORCID iDs}

Stephanie Alley http://orcid.org/0000-0001-9666-5071

Mitch J Duncan http://orcid.org/0000-0002-9166-6195

\section{REFERENCES}

1 Hupin D, Roche F, Gremeaux V et al. Even a low-dose of moderateto-vigorous physical activity reduces mortality by $22 \%$ in adults aged $\geq 60$ years: a systematic review and meta-analysis. Br J Sports Med 2015;49:1262-7.

2 Bauman A, Merom D, Bull FC, et al. Updating the Evidence for Physical Activity: Summative Reviews of the Epidemiological Evidence, Prevalence, and Interventions to Promote "Active Aging". Gerontologist 2016;56:S268-80.

3 Australian Bureau of Statistics. National Health Survey: First Results, 2017-18. Canberra, Australia: ABS, 2019.
4 Medibank Private. The cost of physical inactivity. Australia: Medibank Health Foundation, 2008.

5 Australian Institute of Health and Welfare. Older Australia at a glance. Canberra, Australia: AlHW, 2018.

6 Productivity Commission. An ageing Australia: Preparing for the future, in Commission Research Paper. Canberra: Australian Government, 2013.

7 Davies CA, Spence JC, Vandelanotte C, et al. Meta-Analysis of internet-delivered interventions to increase physical activity levels. Int $J$ Behav Nutr Phys Act 2012;9.

8 Alley S, Jennings C, Plotnikoff RC, et al. Web-Based videocoaching to assist an automated computer-tailored physical activity intervention for inactive adults: a randomized controlled trial. $J$ Med Internet Res 2016;18:e223.

9 Australian Communications and Media Authority. Digital lives of older Australians, in Research snapshots. Canberra, Australia, 2016.

10 Stockwell S, Schofield P, Fisher A, et al. Digital behavior change interventions to promote physical activity and/or reduce sedentary behavior in older adults: a systematic review and meta-analysis. Exp Gerontol 2019;120:68-87.

11 Wijsman CA, Westendorp RG, Verhagen EA, et al. Effects of a web-based intervention on physical activity and metabolism in older adults: randomized controlled trial. J Med Internet Res 2013;15:e233.

12 Cook RF, Hersch RK, Schlossberg D, et al. A web-based health promotion program for older workers: randomized controlled trial. $J$ Med Internet Res 2015;17:e82.

13 Ammann R, Vandelanotte $\mathrm{C}$, de Vries $\mathrm{H}$, et al. Can a websitedelivered computer-tailored physical activity intervention be acceptable, usable, and effective for older people? Health Educ Behav 2013;40:160-70.

14 Broekhuizen K, Kroeze W, van Poppel MNM, et al. A systematic review of randomized controlled trials on the effectiveness of computer-tailored physical activity and dietary behavior promotion programs: an update. ann. behav. med. 2012;44:259-86.

15 Vandelanotte C, Duncan MJ, Maher CA, et al. The effectiveness of a web-based Computer-Tailored physical activity intervention using Fitbit activity Trackers: randomized trial. J Med Internet Res 2018;20:e11321.

16 Alley S, Schoeppe S, Guertler D, et al. Interest and preferences for using advanced physical activity tracking devices: results of a national cross-sectional survey. BMJ Open 2016;6:e011243.

17 Patel MS, Foschini L, Kurtzman GW, et al. Using wearable devices and Smartphones to track physical activity: initial activation, sustained use, and step counts across sociodemographic characteristics in a national sample. Ann Intern Med 2017;167:755-7.

18 Cardinal BJ, Esters J, Cardinal MK. Evaluation of the revised physical activity readiness questionnaire in older adults. Medicine \&amp Science in Sports \&amp Exercise 1996;28:468-72.

19 Alley Set al. A focus group study of older adults' perceptions and preferences towards web-based physical activity interventions. Informatics for Health and Social Care In Press, 2019.

20 Ajzen I. Attitudes, personality, and behaviour. Illinois, USA: The Dorsey Press, 1988.

21 Bandura A. Social foundations of thought and action: a social cognitive theory. New Jersey, USA: Prentice-Hall, 1986.

22 Michie S, Ashford S, Sniehotta FF, et al. A refined taxonomy of behaviour change techniques to help people change their physical activity and healthy eating behaviours: the CALO-RE taxonomy. Psychol Health 2011;26:1479-98.

23 van Hees VT, Gorzelniak L, Dean León EC, et al. Separating movement and gravity components in an acceleration signal and implications for the assessment of human daily physical activity. PLoS One 2013;8:e61691.

24 Rowlands AV, Yates T, Davies M, et al. Raw Accelerometer data analysis with GGIR R-package: does Accelerometer brand matter? Med Sci Sports Exerc 2016;48:1935-41.

25 Hildebrand M, VAN Hees VT, Hansen BH, et al. Age group comparability of raw accelerometer output from wrist- and hip-worn monitors. Med Sci Sports Exerc 2014;46:1816-24.

26 Sasaki JE, John D, Freedson PS. Validation and comparison of ActiGraph activity monitors. J Sci Med Sport 2011;14:411-6.

27 Blank G, Groselj D. Dimensions of Internet use: amount, variety, and types. Information, Communication \& Society 2014;17:417-35.

28 Vandelanotte C, Short C, Plotnikoff RC, et al. TaylorActive examining the effectiveness of web-based personally-tailored videos to increase physical activity: a randomised controlled trial protocol. BMC Public Health 2015;15:1020.

29 Eastin MS, LaRose R. Internet self-efficacy and the psychology of the digital divide. J Comput-Mediat Commun 2000;6. 
30 Australian Institute of Health and Welfare. The Active Australia Survey. A guide for manual implementation, analysis and reporting. Canberra, Australia: AlHW, 2003.

31 Brown WJ, Trost SG, Bauman A, et al. Test-Retest reliability of four physical activity measures used in population surveys. Journal of Science and Medicine in Sport 2004;7:205-15.

32 Heesch KC, Hill RL, van Uffelen JGZ, et al. Are active Australia physical activity questions valid for older adults? Journal of Science and Medicine in Sport 2011;14:233-7.

33 Chau JY, van der Ploeg HP, Dunn S, et al. A tool for measuring workers' sitting time by domain: the workforce sitting questionnaire. Br J Sports Med 2011;45:1216-22.

34 Centers for Disease Control and Prevention. Behavioral risk factor surveillance system (BRFSS), 2019. Available: https://www.cdc.gov/ brfss/ [Accessed June 2019].

35 Buysse DJ, Reynolds CF, Monk TH, et al. The Pittsburgh sleep quality index: a new instrument for psychiatric practice and research. Psychiatry Res 1989;28:193-213.

36 Goodger B, Byles J, Higganbotham N, et al. Assessment of a short scale to measure social support among older people. Aust $N Z J$ Public Health 1999;23:260-5.
37 Resnick B, Nahm ES. Reliability and validity testing of the revised 12 -Item short-form health survey in older adults. J Nurs Meas 2001;9:151-61.

38 Good GA, La Grow SJ, Alpass FM. A study of older adults: observation of ranges of life satisfaction and functioning. $N Z J$ Psychol 2011;40.

39 Diener E, Emmons RA, Larsen RJ, et al. The satisfaction with life scale. J Pers Assess 1985;49:71-5.

40 Cleary PD, Jette AM. Reliability and validity of the functional status questionnaire. Qual Life Res 2000;9:747-53.

41 Jette AM, Davies AR, Cleary PD, et al. The functional status questionnaire: reliability and validity when used in primary care. $J$ Gen Intern Med 1986;1:143-9.

42 Brooke J. SUS - a quick and dirty usability scale. In: Jordan PW ed. Usability evaluation in industry. London: Taylor and Francis, 1996: 194.

43 Alley SJ, Kolt GS, Duncan MJ, et al. The effectiveness of a web 2.0 physical activity intervention in older adults - a randomised controlled trial. Int J Behav Nutr Phys Act 2018;15. 